\title{
Clinicoepidemiological study of fixed drug eruption in tertiary care hospital
}

\author{
Pranav H. Ladani*, Neela V. Bhuptani, Bharti K. Patel, Sagar R. Bhimani
}

Department of DVL (skin), P. D. U. Govt. Medical College and Hospital, Rajkot, Gujarat, India

Received: 29 December 2021
Revised: 07 February 2022
Accepted: 08 February 2022

*Correspondence:

Dr. Pranav H. Ladani,

Email: Pranavladani99@gmail.com

Copyright: (C) the author(s), publisher and licensee Medip Academy. This is an open-access article distributed under the terms of the Creative Commons Attribution Non-Commercial License, which permits unrestricted non-commercial use, distribution, and reproduction in any medium, provided the original work is properly cited.

\begin{abstract}
Background: Adverse cutaneous drug reactions pose diagnostic difficulties due to a varied clinical manifestations and broad categories of causative agents. Fixed drug eruptions (FDE) are one of them. Present study aims i) to record various clinical features of FDE, their causative agents and ii) to study the pattern of morbidity in patients with FDE in a tertiary care hospital, Rajkot, Gujarat, India.

Methods: The 88 patients with FDEs attending department of dermatology, venereology and leprosy at PDU govt. medical college and hospital, Rajkot, Gujarat from September 2018 to September 2020 were included after informed consent. After taking thorough history, complete blood count and biochemical tests were done. HIV testing was done in severe reactions with generalised involvement. Appropriate treatment was given with counselling regarding the offending drug for prevention of reaction in future.

Results: The male patients were more affected than female patients with M: F ratio of 1.3:1. The most common age group affected was $21-30$ years (22.7\%). Antimicrobials were the most common offending drugs (43.2\%). None of the patients were HIV reactive in our study. No mortality was reported in our study.

Conclusions: The patterns of FDE and the causative drugs are remarkably different in our study. Knowledge of patterns and the causative agents helps in prevention of same reactions in future in patients.
\end{abstract}

Keywords: FDEs, Antimicrobials, Adverse cutaneous drug reactions

\section{INTRODUCTION}

An adverse drug reaction (ADR) is defined as an undesirable clinical manifestation resulting from administration of a particular drug; this includes reactions due to overdose, predictable side effects and unanticipated adverse manifestations. ${ }^{1}$ FDE is benign cutaneous reaction which rarely results in morbidity and mortality. With the discovery of the new drugs, almost every day a new drug enters in medical treatment of diseases. The use of new drugs has been associated with increased incidences and various modes of presentation of drug reactions. The mainstay of the treatment includes cessation of offending drugs. The objectives of present study are to record various clinical features of FDE, their causative agents and to study the pattern of morbidity in patients with FDE in a tertiary care hospital, Rajkot, Gujarat, India.

\section{METHODS}

The present study is an open, prospective, observational study, carried out in the department of dermatology, venereology and leprosy at PDU government medical college and hospital, Rajkot, Gujarat during a period of 2 years from September 2018 to September 2020. MS office excel 2009 (Build 13231.20262) software was used to tabulate and analyse the data. All patients attending the dermatology OPD and indoor patients with FDE s due to systemic drugs were included in the study. The clinical history of all the patients was recorded according to 
preformed proforma. Precise history of drug intake including allopathic, homeopathic, ayurvedic medicines along with its temporal correlation with initiation of the symptoms was elicited with an emphasis on whether it was prescribed or self-administered.

Careful history regarding relevant dermatological disorders like atopy or systemic co-morbidities, past and family history of drug eruption was noted. Final diagnosis was made after excluding other possible causes which mimic the same clinical manifestations. Morphology of the lesions, duration, associated mucosal and systemic involvement were recorded. Improvement on drug withdrawal was observed. Rechallenge was not attempted in any of the patients. If multiple drugs were suspected in a case, the most likely offending drug was noted with help of past history of reactions and was confirmed by resolution of the reaction on withdrawing the drug.

All routine investigations including complete blood count, urine routine and microscopic examination, liver function tests, renal function tests, random blood sugar (RBS) were performed in all patients. HIV testing was done in cases of generalised fixed drug reactions and in those with associated history of chronic fever, diarrhoea, weight loss, tuberculosis, opportunistic infections, etc. Appropriate treatment was given to each patient. All patients were counselled and educated to avoid self-administration of the offending drugs. Each patient was given a list of drugs to be avoided in future.

\section{RESULTS}

A total of 180 patients were diagnosed as adverse cutaneous drug reactions among which 88 patients were diagnosed with FDEs. The number of male patients were $49(55.7 \%)$ and female patients were 39 (44.3\%) with male: female ratio being 1.3:1. The most common age group being affected was $21-30$ years $(22.7 \%)$ followed by $31-40$ years $(20.5 \%)$, 41-50 years $(19.3 \%), 11-20$ years (13.6\%) and 51-60 years (12.5\%) (Table 1). Drugs were prescribed by a medical professional in 48 cases $(54.5 \%)$, while self-administered in 40 cases $(45.5 \%)$. The route of administration was found to be oral in all patients. History of same cutaneous drug reactions in the past was present in 36 patients $(40.9 \%)$. Lesions were generalised in 22 cases $(25 \%)$ and localised in 66 cases $(75 \%)$. Antimicrobial group of drugs $(43.2 \%)$ was most common drug group to cause FDEs followed by group of unknown drugs (37.5\%), NSAIDs (9.1\%), antifungals (9.1\%), antiepileptics $(1.2 \%)$ and antihypertensive $(1.2 \%)$ (Table 2). Among antimicrobials, fluoroquinolones (55.3\%) were most common drug group to cause FDE followed by antiamoebics $(34.2 \%)$, tetracyclines $(15.8 \%)$, penicillin (7.9\%), sulphonamides $(5.3 \%)$, cephalosporins $(2.7 \%)$. In our study, various patterns of FDEs were seen like pigmented FDEs in $63.6 \%$ (56), bullous FDES in $21.6 \%$ (19) and generalised FDEs in $14.8 \%$ (13) (Table 3). None of the patient was HIV reactive in our study.
Table 1: Age and sex distribution of drug eruption in the present study.

\begin{tabular}{|lllll|}
\hline $\begin{array}{l}\text { Age } \\
\text { Years) }\end{array}$ & Male & Female & Total & $\begin{array}{l}\text { Percentage } \\
(\%)\end{array}$ \\
\hline $\mathbf{1 - 1 0}$ & 1 & - & 1 & 1.14 \\
\hline $\mathbf{1 1 - 2 0}$ & 8 & 4 & 12 & 13.64 \\
\hline $\mathbf{2 1 - 3 0}$ & 12 & 8 & 20 & 22.73 \\
\hline $\mathbf{3 1 - 4 0}$ & 8 & 10 & 18 & 20.46 \\
\hline $\mathbf{4 1 - 5 0}$ & 9 & 8 & 17 & 19.32 \\
\hline $\mathbf{5 1 - 6 0}$ & 7 & 4 & 11 & 12.50 \\
\hline $\mathbf{6 1 - 7 0}$ & 4 & 5 & 9 & 10.23 \\
\hline
\end{tabular}

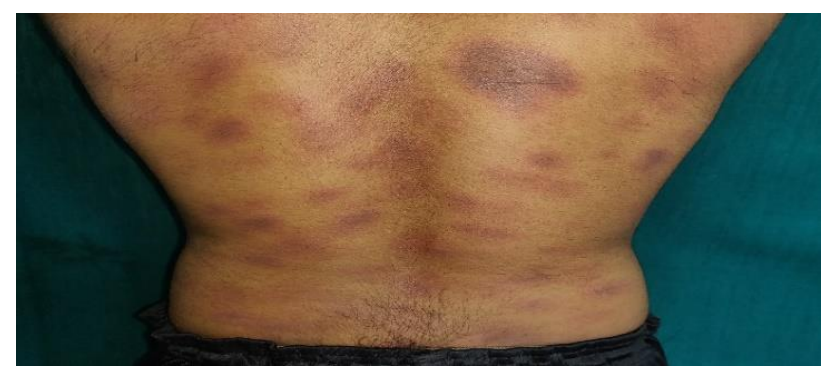

Figure 1: Initial erythematous lesions of bullous FDE.

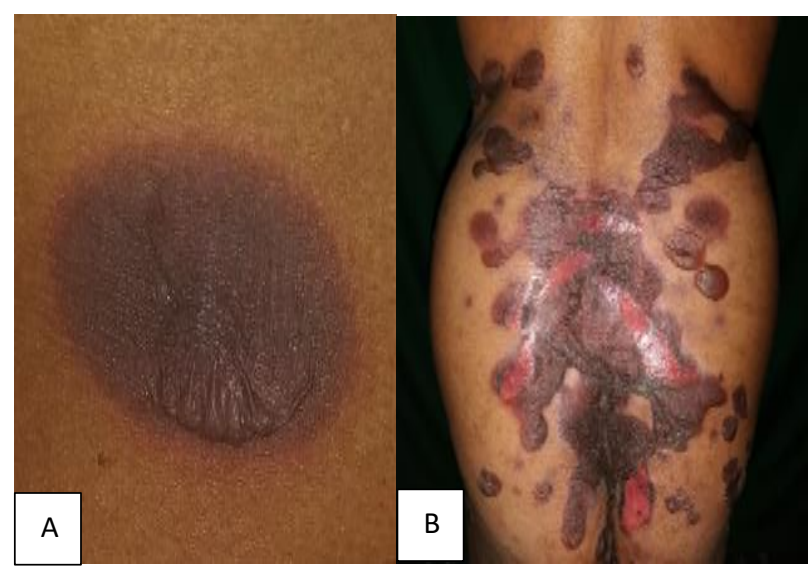

Figure 2 (A and B): Cutaneous lesions of bullous FDE.

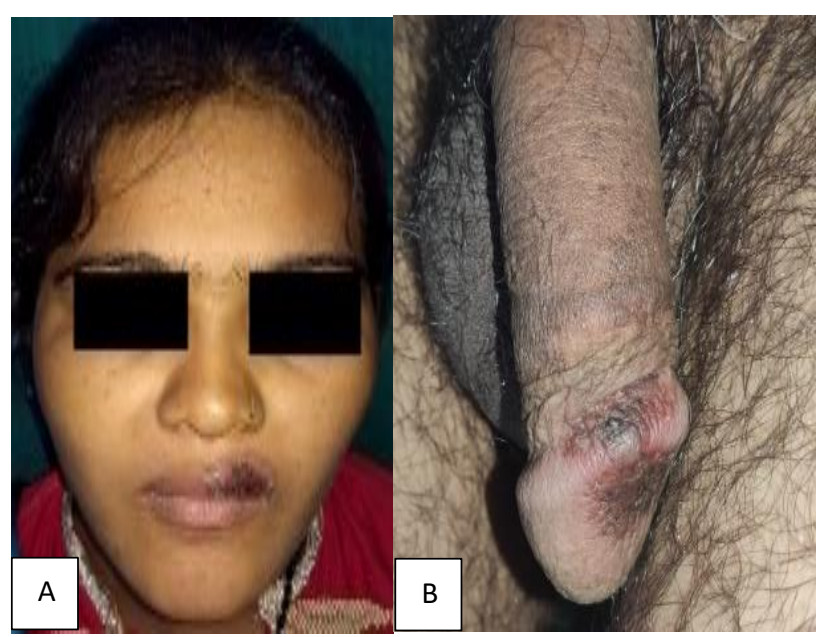

Figure 3 (A and B): Mucosal lesion of FDE. 
Table 2: Drugs causing fixed drug eruptions.

\begin{tabular}{|c|c|c|c|}
\hline Offending drug & $\begin{array}{l}\text { No. of patients' present } \\
\text { study }(\%)\end{array}$ & Marfatia et al (2008) (\%) & Singh et al (1999) (\%) \\
\hline \multicolumn{4}{|l|}{ Antimicrobials } \\
\hline Ofloxacin & $5(5.68)$ & - & - \\
\hline Doxycycline & $4(4.55)$ & $01(1.6)$ & $02(12.50)$ \\
\hline Ciprofloxacin+metronidazole & $4(4.55)$ & - & - \\
\hline Norfloxacin & $3(3.41)$ & - & - \\
\hline Levofloxacin & $3(3.41)$ & - & - \\
\hline Ciprofloxacin & $3(3.41)$ & - & - \\
\hline Cotrimoxazole & $2(2.27)$ & $18(29.5)$ & $8(50)$ \\
\hline Amoxicillin & $2(2.27)$ & $02(3.2)$ & - \\
\hline Ofloxacin+ornidazole & $2(2.27)$ & - & - \\
\hline Doxycycline+ metronidazole & $2(2.27)$ & - & - \\
\hline Metronidazole & $2(2.27)$ & - & - \\
\hline Norfloxacin+ tinidazole & $1(1.14)$ & - & - \\
\hline Cefixime & $1(1.14)$ & - & - \\
\hline Nitrofurantoin & $1(1.14)$ & - & - \\
\hline Sulfadiazine & - & $02(3.2)$ & - \\
\hline Rifampicin & - & - & $01(6.25)$ \\
\hline \multicolumn{4}{|l|}{ Antifungals } \\
\hline Fluconazole & $8(9.1)$ & - & - \\
\hline Fluconazole+secnidazole & $1(1.14)$ & - & - \\
\hline Griseofulvin & - & $01(1.6)$ & $01(6.5)$ \\
\hline \multicolumn{4}{|l|}{ NSAIDs } \\
\hline Ibuprofen & $1(1.14)$ & $05(8.1)$ & - \\
\hline Oxyphenbutazone & - & - & $04(25)$ \\
\hline Diclofenac sodium & $1(1.14)$ & $03(4.9)$ & - \\
\hline Paracetamol & $1(1.14)$ & $02(3.2)$ & - \\
\hline Paracetamol+diclofenac & $1(1.14)$ & - & - \\
\hline Tramadol & - & $01(1.6)$ & - \\
\hline Metamizole & - & $02(3.25)$ & - \\
\hline Other NSAIDs & $5(5.68)$ & $06(9.8)$ & - \\
\hline \multicolumn{4}{|l|}{ Antiepileptics } \\
\hline Carbamazepine & $1(1.14)$ & $02(3.2)$ & - \\
\hline Phenytoin & - & $01(1.6)$ & - \\
\hline Glyceryl trinitrate & $1(1.14)$ & - & - \\
\hline Unknown & $33(37.50)$ & $15(23.6)$ & - \\
\hline Total & $88(100)$ & $61(100)$ & $16(100)$ \\
\hline
\end{tabular}

Table 3: Patterns of FDE.

\begin{tabular}{|ll|}
\hline Pattern of FDEs & No. of patients (\%) \\
\hline Pigmented & $56(63.6)$ \\
\hline Bullous & $19(21.6)$ \\
\hline Generalised & $13(14.8)$ \\
\hline
\end{tabular}

\section{DISCUSSION}

FDE is characterized by recurrence of same lesions at same site after intake of same drug or member of related group of drugs.

FDEs have been reported in patients as young as 1.5 years and as old as 87 years. The mean age at presentation is 30.4 years in males and 31.3 years in females. ${ }^{2}$ In our study, the most common age group being affected was 21-30 years
(22.7\%) followed by 31-40 years $(20.5 \%)$. Males were more commonly affected than females in our study. HLAB22 is associated with increased incidence of FDE. ${ }^{3}$ It may occur within 30 minutes to 8 hours after intake of drugs but during initial attack it may delay up to 2 weeks.

The pathomechanism of FDE is not fully explained. The offending drug may act as a hapten that preferentially binds to basal keratinocytes, leading to an inflammatory response. The expression of intracellular adhesion molecule (ICAM-1) is increased at localised skin lesions suggesting trigger for activation of disease-specific associated epidermal T-cells. The epidermal basal layer shows throughout distribution of CD8+ T-cells, resembles effector memory T-cells which enhance severe tissue injury by producing large amount of IFN-Gamma. ${ }^{4,5}$ The CD8 cells isolated from active lesions have also shown to 
express alpha E beta 7, a ligand for E-cadherin, which may further contribute to the lymphocyte's ability to localize to the epidermis. Other cell surface molecules, such as CLA/alpha4beta1/CD4a, that bind E-selectin/vascular cellular adhesion molecule-2/ICAM1 help to further attract CD8 cells to the area. ${ }^{6}$

The initial eruption is often solitary and frequently located on the lip or external genitalia. ${ }^{7}$ Rarely, it can be present with oral involvement only. Lesions are more common on the limbs than on the trunk; the hands and feet, genitalia and perianal areas are favoured sites. Perioral and periorbital lesions may occur. Genital and oral mucous membranes may be involved in association with skin lesions or alone. On examination, the most common clinical manifestation is the pigmented FDE, which manifests as round or oval, sharply demarcated erythematous plaques or patches located on the lip, hip, sacrum, or genitalia. ${ }^{7}$ The centre of the patch may blister or become necrotic. The lesions persist from days to weeks and then resolve slowly with residual oval hyperpigmented patches. ${ }^{8}$

The eruption may initially be morbilliform, scarlatiniform or erythema multiforme-like; urticarial, nodular or eczematous lesions are less common. The reactivation of old lesions also is associated with the development of new lesions at other sites. Patients may not be cognizant that a drug, nutritional supplement, over the counter medication or rarely, food (e.g., fruits, nuts) those triggered the skin reaction.

The types of FDEs include pigmenting FDE, generalized or multiple FDE, linear FDE, wandering FDE, nonpigmenting FDE, bullous FDE, eczematous FDE, urticarial FDE, erythema dyschromicum perstans-like FDE, vulval and oral FDE, psoriasiform, etc.

The common drugs causing FDEs include nonsteroidal anti-inflammatory drugs, paracetamol, co-trimoxazole, tetracyclines, penicillin, metronidazole, rifampicin, erythromycin, barbiturates, carbamazepine, phenobarbitone, calcium channel blockers, angiotensin converting enzyme inhibitors, omeprazole, iodinated contras, etc. ${ }^{9}$

In our study, the number of male patients were $49(55.7 \%)$ and female patients were $39(44.3 \%)$ with male: female ratio being $1.3: 1$. The most common age group being affected was $21-30$ years $(22.7 \%)$ followed by $31-40$ years $(20.5 \%), 41-50$ years $(19.3 \%), 11-20$ years $(13.6 \%)$ and 51-60 years $(12.5 \%)$ because self-administration and polypharmacy are more common in this age group. Antimicrobial group of drugs (43.2\%) were most common drug group to cause FDEs followed by group of unknown drugs $(37.5 \%)$, NSAIDs $(9.1 \%)$, antifungals $(9.1 \%)$, antiepileptics $(1.2 \%)$ and antihypertensive $(1.2 \%)$. The common drug group causing FDEs in studies done by Marfatia et al and Singh et al were also antimicrobials. Fluoroquinolones $(55.3 \%)$ were most common drug group to cause FDE in present study whereas co-trimoxazole was most common culprit in studies done by Marfatia et al $(29.5 \%)$ and Singh et al $(50 \%) .{ }^{11,12}$

Histological examination of acute lesion showed an interface dermatitis with vacuolar degeneration and Civatte bodies (necrotic keratinocytes). ${ }^{10}$ The overall histological findings are similar to erythema multiforme. Rarely, the inflammatory infiltrate consists of lymphocytes, eosinophils and neutrophils. Older or chronic lesions show pigmentary incontinence, mild acanthosis and hyperkeratosis and few inflammatory cells.

The laboratory investigations are not much useful in diagnosis of FDE. Peripheral eosinophilia can be associated with drug reactions. Patch test is useful in case of non-steroidal anti-inflammatory drugs. The biopsy is diagnostic procedure of choice.

The main aim of treatment is identification of offending suspected agents and removal of them from future prescriptions. Symptomatic treatment with antihistaminic and topical steroids are enough most of times. Antibiotics and proper wound care should be provided if secondary infection is present. In severe reactions, cyclosporine can be used. The re-challenge with same drug should be avoided unless suitable substitute is not available.

\section{CONCLUSION}

The patterns of FDE and the offending medications are noticeably different in present study. Knowledge of patterns and their offending agents helps in early diagnosis and treatment with early cessation of those agents. Thus, it helps in prevention in morbidities and mortality as consequences of reactions. The study also guides about the counselling of patients regarding the recurrence of same reaction with same molecules and prevention of reaction in future.

\section{Funding: No funding sources Conflict of interest: None declared \\ Ethical approval: The study was approved by the Institutional Ethics Committee}

\section{REFERENCES}

1. Breathnach SM. Drug Reactions. In. Tony Burns, Stephen Breathnach, Neil Cox, Christopher Griffiths editor. Rook's Textbook of dermatology,8th ed. Wiley-Blackwell publications. 2010;4(75):75.1-177.

2. Mahboob A, Haroon TS. Drugs causing fixed eruptions: a study of 450 cases. Int J Dermatol.1998;37:833-8.

3. Butler D, Elston D. Fixed Drug Eruptions. Available at: $\quad$ emedicine.medscape.com/article/1336702overview. Accessed on March 11, 2009.

4. Mizukawa Y, Shiohara T. Fixed drug eruption: a prototypic disorder mediated by effector memory $\mathrm{T}$ cells. Curr Allergy Asthma Rep. 2009;9(1):71-7. 
5. Shiohara T, Mizukawa Y. Fixed drug eruption: a disease mediated by self-inflicted responses of intraepidermal T Cells. Eur J Dermatol. 2007;17:2018.

6. Teraki Y, Shiohara T. IFN-gamma-producing effector CD8+ T cells and IL-10-producing regulatory CD4+ $\mathrm{T}$ cells in fixed drug eruption. $\mathrm{J}$ Allergy Clin Immunol. 2003;112(3):609-15.

7. Ozkaya-Bayazit E. Specific site involvement in fixed drug eruption. J Am Acad Dermatol. 2003;49(6):1003-7.

8. Bolognia JL, Jorizzo JL, Rapini RP. Fixed drug eruptions. In: Dermatology. London, England: Mosby; 2003:344-5.

9. Rook's Textbook of Dermatology, Ninth Edition. Edited by Christopher Griffiths, Jonathan Barker, Tanya Bleiker, Robert Chalmers and Daniel Creamer, $9^{\text {th }}$ edition. 2016;118:11-4.
10. Patel RM, Marfatia YS. Clinical study of cutaneous drug eruptions in 200 patients. Indian J Dermatol Venereol Leprol. 2008;74:430.

11. Singh KK, Shrinivas CR, Krupashankar DS, Naik RPC. Study of thirty-three cases of fixed drug eruption, Indian J Dermatol Venereol Leprol. 1990;56:123-4.

12. Weedon D. The lichenoid reaction pattern ('interface dermatitis'). Skin Pathology. $2^{\text {nd }}$ ed. London, England: Churchill Livingstone; 2002;42-3.

Cite this article as: Ladani PH, Bhuptani NV, Patel BK, Bhimani SR. Clinicoepidemiological study of fixed drug eruption in tertiary care hospital. Int $\mathbf{J}$ Basic Clin Pharmacol 2022;11:132-6. 